\title{
Integrating Foresight, Artificial Intelligence and Data Science to Develop Dynamic Futures Analysis
}

\author{
Raúl Trujillo-Cabezas ${ }^{1 *}$
}

${ }^{1}$ School of Management, Universidad Externado de Colombia, Bogota D.C., COLOMBIA

*Corresponding Author: raul.trujillo@uexternado.edu.co

Citation: Trujillo-Cabezas, R. (2020). Integrating Foresight, Artificial Intelligence and Data Science to Develop Dynamic Futures Analysis. Journal of Information Systems Engineering and Management, 5(3), em0120. https://doi.org/10.29333/jisem/8428

\begin{tabular}{|c|c|}
\hline ARTICLE INFO & ABSTRACT \\
\hline Published: 30 Jul. 2020 & $\begin{array}{l}\text { The paper discusses the role of integrating Artificial Intelligence (AI) and Data Science (DS) with the strategic } \\
\text { foresight. That is, combining the art of conjecture with several algorithms available in the literature. The } \\
\text { combination between qualitative and quantitative methods offers a new dynamic adaptation route to face the } \\
\text { rapidly changing environment, to make strategic design more flexible in the long term. The proposal uses the ISSM } \\
\text { framework as a notion of a Strategic Early Warning System (SEWS). Thus, an ISSM framework could assist } \\
\text { organizations during the transition from dealing with discontinuities or strategic surprises to a new normal, using } \\
\text { new capacities to creating knowledge of futures. The purpose is help to develop the component named } \\
\text { competitive intelligence (CI) architecture to create knowledge about the future, improving continuous learning, } \\
\text { and promote the capacity to adaptation. Therefore, anticipation, learning and strategic adaptation, are key } \\
\text { attributes for building strategic flexibility that responds to several challenges. }\end{array}$ \\
\hline
\end{tabular}

Keywords: strategic foresight, artificial intelligence, data science, early warning system, dynamic analysis

\section{INTRODUCTION}

This paper aims to contribute to the integration of foresight with the Al and DS. The foresight approach (Husserl, 1931) is the core of the methodology. The combination between art of the conjecture, Al and DS could offer a route to integrate qualitative and quantitative methods for recognition of endo- and exo-signals to reduce the uncertainty in the process of long-term strategic reflection. This is, the need to contribute for a new vision of the strategic intelligence process that is developed in this paper, which includes two issues: a) developing an $\mathrm{Cl}$ component architecture using a ISSM framework (Koyré, 1928) to improve a "direct a preactive (anticipating changes)" (Carlsson and Fullér, 1996: 338) that shows three layers, and b) developing an experimental case, that shows an integration route to make a systemic reflection on the future.

This is an environmental monitoring process that can be done repeatedly recognizing endo- and exo-signals until a cognitive model suggests a new option to select the most plausible scenario with different levels of flexibility for recognize anticipatory behavior. The anticipation process can improve the understanding of strategic design of the systemic structure, during the elaboration of possible futures (futuribles) or scenarios.

The opportunities that arise apply to wide range of strategic planning challenges. This is an integration of hybrid modeling practices using strategic foresight with Al and DS algorithms.

The current approach hopes to help create a new route to make a dialectic of a progressive understanding of the future, and stimulate strategic innovation processes, systematically offering the development of long-term competitive capabilities in many fields of action.

Thus, stimulating the ideas of integrates qualitative and quantitative sources promotes three key features: a) creating knowledge about the future through anticipation and forecasting, b) promoting changes in organizational behavior through continuous learning, and c) promoting the capacity to adaptation (Berger, 1957). Therefore, anticipation, learning and strategic adaptation, are the subject of discussion in this paper.

\section{BASIC THEORIES}

The main goal of foresight is to help create a dialectic to reduce uncertainty in the process of long-term strategic reflection (Calof et al., 2018). Foresight, offers a way to stimulate innovation processes around strategic reflection, from phenomenological 
approaches such as Gaston Bachelar (Cabezas and Verdegay, 2019; De Jouvenel, 1967) who developed a distinctive phenomenological approach, with respect to Husserl (Agami et al., 2010; Husserl, 1936), Koyré (Amer et al., 2013; Forrester, 1970), Marcel (Fernández et al., 2018; Marcel, 1926) and many others.

\section{Phenomenology of Bachelard}

The work of Bachelard on phenomenology offers a perspective of the relations of conscience with diverse environments of human beings and things, suggesting that modern scientific observation needs more than immediate experiences. That is, from the perspective of long-term strategic reflection, value judgments and recognition of trends are part of the multiple subjective options of methods (Slaughter, 1988) designed to facilitate agreement processes during the construction of future scenarios. Many of the methods proposed from the foresight approach are classified as qualitative or semi-qualitative, since the sources are the evaluations carried out in workshops where issues of strategic value are discussed.

\section{The FLighTS Method}

The combination of qualitative and quantitative becomes increasingly important, provided that the notion of scenario is at the center of the inference process that takes place in foresight (Leder, 2010) to meet various decision-making needs. The employment of fuzzy cognitive maps (FCM) (Schwarz, 2009; Trujillo-Cabezas, 2008) and Trend Impact Analysis (TIA) (Schwarz, 2005) methods offer an answer in this direction (Koyré, 1928).

The use of FCM reduces the fundamental differences between qualitative and quantitative methods (Škulj, 2012). While the Trend Impact Analysis (TIA) method (Ackoff, 1981; Gilad, 2006; Raynor, 2004; Reinhardt, 1984) offers new perspectives for its application. It means that, given the complex nature of studying the future (Goal, 2019), there are many solutions that can satisfy the constraints of state variables (key factors), in the context of the problem and the objectives of study, which are many times in conflict, due to the interests of decision makers. The mixed methods using Meta-Foresight which is "oriented toward strengthening the inference process in light of the validity criteria used in the practice of strategic foresight" (Kosko, 1986a: xv).

The Meta-Foresight approach introduces a novel process of building a cone of scenarios called FLighTS (Calof et al., 2018; Kosko, 1986a) that offers the opportunity to integrate Al from the field of Soft Computing ${ }^{1}$ with the art of conjecture used in the strategic foresight. This type of combination favors the construction of cognitive models that help develop a systemic understanding of strategic design. Cognitive modeling integrates value judgments from decision makers with the results of endoand exo-signal collection using various methods available in the AI and DS literature. Therefore, it becomes possible to elaborate conjecture sets about the futures, which are grouped through the notion of cone of scenarios, thanks to the FLighTS iteration that has been developed. Therefore, this component corresponds to the strategic layer of the proposed ISSM framework, understood as the macro level. Two additional lower layers are the meso level and the micro level. Thus, ISSM is a multi-layer framework (Dzutsati, 2019).

The meso-level called systemic level, has the purpose of recognizing and trying to identify trends and understand the phenomena. Therefore, approaches such as ABM can help to the modeling of complex social systems. ABM offers the opportunity to ask "What if" questions during simulations to help decision makers improve their understanding of social phenomena and dynamics that can affect strategic design. ABM is an Al-based inference route that, unlike the artifacts commonly used in DS, offers explanatory mechanisms for the results obtained when executing the models. The results of inferences made at the systemic level are an input for the FLighTS method.

A systematic collection of endo- and exo-signal, using DS and Cl practices (Gordon and Hayward, 1968; Kosko, 1986b; Meadows, 1989), helps decision makers to obtain forecasts and recognize patterns associated with topics of interest related to strategic design. These results can be used as input for the development of the systemic and/or strategic analysis of the higher levels, raising the level of discussion in favor of decision makers. Data sources can be multiple and diverse, from the execution of "data wrangling" processes to the use of techniques such as Linear Regression, Classification and Regression Trees or Support Vector Machines among other algorithms available in the literature. The tasks of data analysis and the application of $\mathrm{Cl}$ practices (Godet and Roubelat, 1996) are the main objective of the micro level called the analytical layer.

The results of the combination between three layers are especially important for decision makers, insofar as they contribute to guide decisions based on the art of conjecture, using additional information from the computational process. Using the FLighTS method, it is possible to integrate three approaches during long-term strategic reflection: AI, DS and foresight. Therefore, the intensive use of computing devices whose choice is determined by $\mathrm{Cl}$ practices (Godet and Roubelat, 1996) contributes to the development of the "flashlight that allows us to illuminate the future" (Bekey and Kogan, 2012).

\section{AN CI COMPONENT ARCHITECTURE TO ISSM MODEL}

The $\mathrm{Cl}$ component (Kosko, 1986b; Meadows, 1989) of the ISSS model represents an architectural proposal to assimilate, systematize and validate what knowledge is available and useful for decision-makers on the behavior of strategic design and its environment. The ISSM framework uses a combination of intuition, creativity and analytics. From a phenomenological perspective, it is essential to combine objectivity and subjectivity (Cabezas and Verdegay, 2019; De Jouvenel, 1967) to adapt to important changes, making strategic design more flexible to reduce uncertainty during a continuum of decision-making processes.

\footnotetext{
${ }^{1}$ Sometimes referred to as computational intelligence.
} 


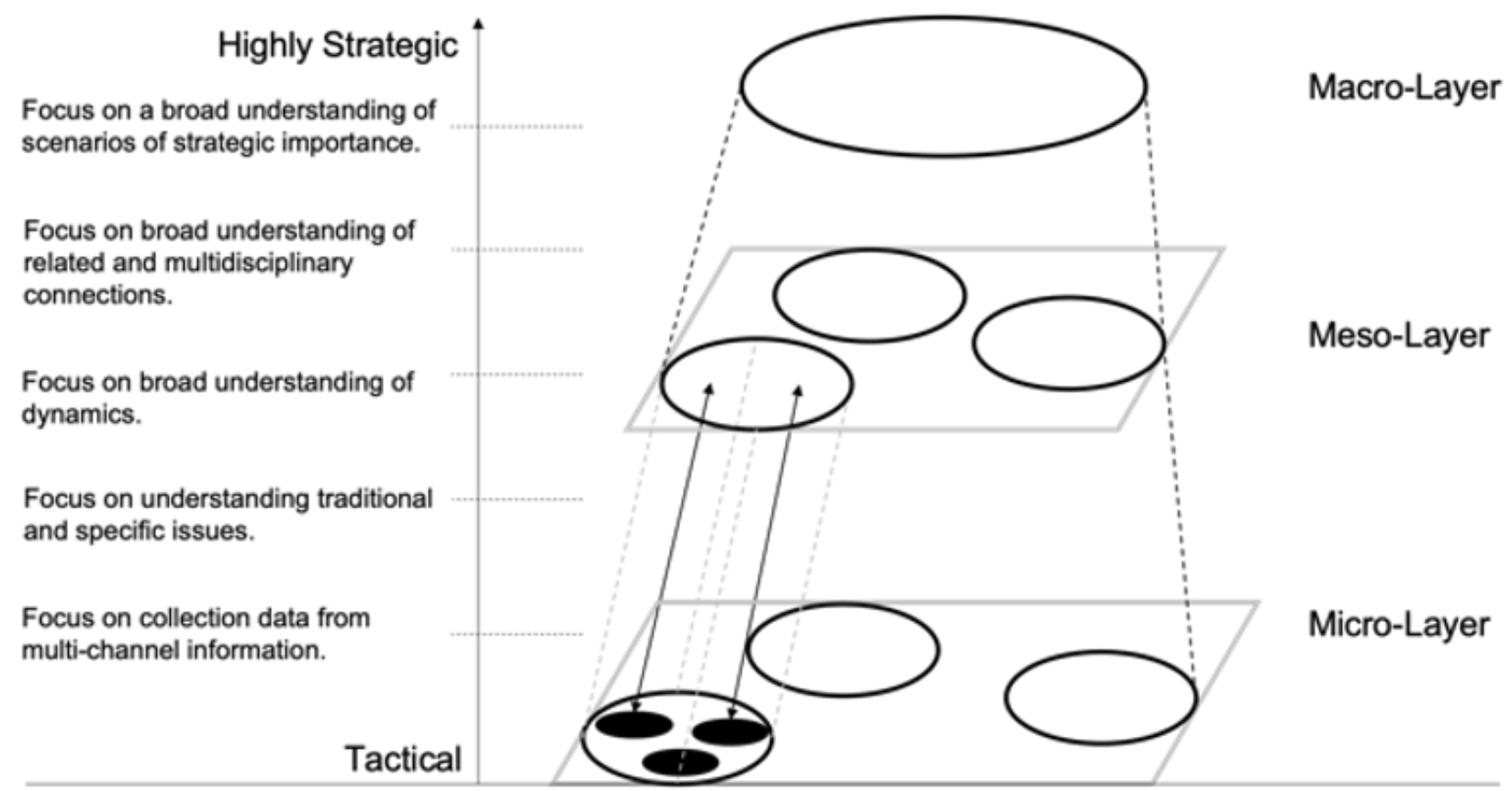

Figure 1. Multi-Layer Planning Process

Source Adapted from (Schwarz, 2005, 2009)

$\mathrm{Cl}$ suggests a way to select the more plausible scenario, using different degrees of flexibility for recognize anticipatory behavior. Thus, the decision-makers have an intuitive, cognitive mapping techniques, a set of future events and their impact utilizing prior knowledge, to face a dynamic environment. The conditions proposed by $\mathrm{Cl}$ (Gordon and Hayward, 1968) to give governance to the endo- and exo-signal recognition process can be synthesized as follows: 1) Defining the strategic and tactical value of the data to be collected, seeking to quantify them as much as possible. 2) Defining the type of data available to collect such as text, images, sound, etc., this implies a certain type of analysis which in turn requires specific tools and skill sets. 3) Identifying the types of analysis that can help respond to strategic expectations, that is, sentiment analysis can help identify general trends, but human experience could recognize or not this as a trend? 4) Executing the collection and analysis of appropriate data. 5) Evaluating, adjusting, and repeating the collection, seeking to quantify the endo- and exo-signals is a systematic approach that will help ensure that the correct data is captured and handled properly. Based on this evaluation, data capture, analytical tactics and expected strategic results can be adjusted and improved.

Thus, during the last three decades, many tools or techniques within the area of strategy and $\mathrm{Cl}$ have been widely used, such as SWOT, Key Success Factor Analysis, Porter's Five Forces, Where-to-Play and How-to-Win, Strategy Under Uncertainty, Strategic Sweet Spot Analysis, Scenario Planning \& Analysis. This approach raises a new way of looking at strategic planning and $\mathrm{Cl}$, making it possible "Delivering the right intelligence, for the right purpose, in the right format, to the right person, in the right place, at the right time" (Godet and Roubelat, 1996: 118), by combining AI, DS and foresight.

\section{How is the Architecture?}

The purpose of this architecture is to describe a cognitive model of TMT (Calof et al., 2015; Marcel and Segond, 1935) collaboration, emphasizing the combination of human decision-making processes with the planned collection of information sources. The architecture includes the characteristics, the stages of collaboration, and the cognitive processes that occur within and between the micro- meso- and macro-level. The architecture has been made to respond to change that is occurring more rapidly than in the past (Ansoff, 1975). Thus, the future is implied by its own behavior and of its environment, the SEWS notion to face the discontinuities or important surprises from internal and external environs. The process has three phases or layers to detect trends, understanding one phenomenon, crossing the borders of contexts (Trujillo-Cabezas and Verdegay, 2020), and finally, describes and/or adjust an appropriate strategic formulation, which is strategic flexibility. Anticipating drivers of change, recognizing contingent elements and defining the range of possible futures. A typical process is illustrated in Figure 1.

The architecture integrates three layers all defined by the strategic goals.

The micro-level consists of general inputs, using systems thinking approaches that can help to simplify thought processes about complex realities, and collaborative process to human or not information processing (e.g. loT devices). Thus, the identification of interrelated and interdependent variables can be achieved, using several DS algorithms and hybridizing these. In order to perform the hybridization, the proposals could vary in their approach including heterogeneous information processing. In general, unsupervised learning (Dickerson and Kosko, 1994; Ghifary et al., 2016) is used from the perspective of statistical modelling, including factor analysis, PCA, ICA, mixtures of Gaussians, state-space models, inference algorithms on graphs, approximate Bayesian inference, Markov chain Monte Carlo, machine/deep learning and many variants and extensions. The aim of this layer is to provide a view of the KPIs associated to strategic goals. Along the way, many cutting-edge ideas and future 
directions could also be reviewed. The focus on collecting multichannel information data is critical, and the understanding of traditional and specific problems could be defined as very important by decision makers.

To illustrate the possibilities, problems of interest that address multiple types of problems at the micro level can be evidenced. In strategic matters for commercial banking, there may be concerns about business practices, early detection of market signals, deepening commitment to customers, significant increase in employee skills, creation of new forms of interaction and commercial interconnection. For an insurance company, there may be problems such as demand estimates, claims, needs of workforce, among others. For the management of a smart city, air quality problems may be relevant with respect to particle measurement, tropospheric ozone, relative humidity, barometric pressure and temperature, traffic variables, among many others. While for an oil and gas industry company, it may be important to recognize the conditions of relationship with the local communities in the territories where it operates.

The meso level is intended to employ the modeling and simulation (M\&S) formalisms used to provide the basis for building executable approaches for real-world systems. M\&S offers a means to improve understanding of problems and identify solutions for a wide range of needs. Possible capacities can be oriented towards the realization of training, planning, or support for decisionmaking in the execution of socioeconomic models. Two key topics must be discussed. The first is modeling formalism, which provides an unambiguous specification for the structure of a model. The second is about simulation techniques, which describe how to generate the behavior of real-world systems. Modeling formalism can include approaches such as ABM, DEVS or Differential Equations. While simulation techniques, generally address Discrete Events, Discrete Time, Numerical and Non-Linear Programming choices. On understanding of dynamics is the main focus. However, the participation of multiple types of experts is essential at this level, to understand the systemic dynamics of the phenomena chosen to model and simulate.

The understanding of the systemic dynamics of the internal or external environment should be represented as follows: For the internal environment an FCM (Kosko, 1986a) is constructed for each key factor of strategic interest, according to the strategic definitions made by the decision makers. For the external environment, an event matrix is constructed using the TIA method (Kosko, 1986a), to help understand its impacts on each performance of the proposed strategic design (Calof et al., 2018).

The macro level aims to make the future a space for long-term strategic reflection. The FLighTS method is used to carry out human evaluations in meetings and workshops to discussed strategic interest. The micro and M\&S level of the meso level are sources for making value judgments and evaluations made by decision makers who participate in meetings in the orbit of the subjective. The FLighTS method helps the representation of hyper-knowledge in strategic formulation processes (Gordon et al., 1974).

To integrate multiple micro level results, multiple cognitive maps are constructed using the FCM method. That is, these endosignals are grouped according to strategic affinity criteria and the results of performing the iteration of each FCM for once; contribute to integrate the nodes of the main FCM that represents the cognitive design of the strategic proposal. Thus, each key factor integrated a low-level FCM using an "Aggregation and recommendation" procedure (Koyré, 1940). In these results, by obtaining a unique design, decision makers-can still make adjustments, using their value judgments. Finally, the event matrices (i.e. exo-signals) that have been obtained when applying the TIA method are integrated and the FLighTS method is executed to recognize a cone of futuribles and continue with strategic reflection (Calof et al., 2018).

\section{EXPERIMENAL CASE}

An experimental case was executed for a Spanish oil company, collecting data and information from one of its drilling operations centers located in the Meta department in Colombia. To configure the requirements of the experimental case, many workshops were held with a team selected from an oil company. These requirements are described below:

The main objective was to identify a set of CSR strategies that could achieve long-term success to improve the relationship rules between the oil company and the local communities in the territories where it operates, helping to reduce uncertainty in the operation and its impacts.

A set of three key factors was selected to define the analysis requirements for the macro-level. The key factors were: 1) Relationship with external social actors. 2) Positioning of the CSR plan with internal interest groups. 3) Making sustainable investments in the communities where the projects are developed.

At the meso-level, eight trends were identified: Degree of confidence in the oil and gas sector, political corruption behavior, poverty, culture and social injustice, dynamics of local governance, social entrepreneurship behavior, social control performance for the oil and gas sector, and culture of collective action. For each of the trends, an ABM-based was designed and developed using Netlogo. Figure 2 shows the design to the political corruption behavior trend. Many workshops were running to improve understanding of selected trends. The findings from the M\&S activity allowed the CSR team members to develop a trend analysis matrix to use when the FLighTS method is executed. 


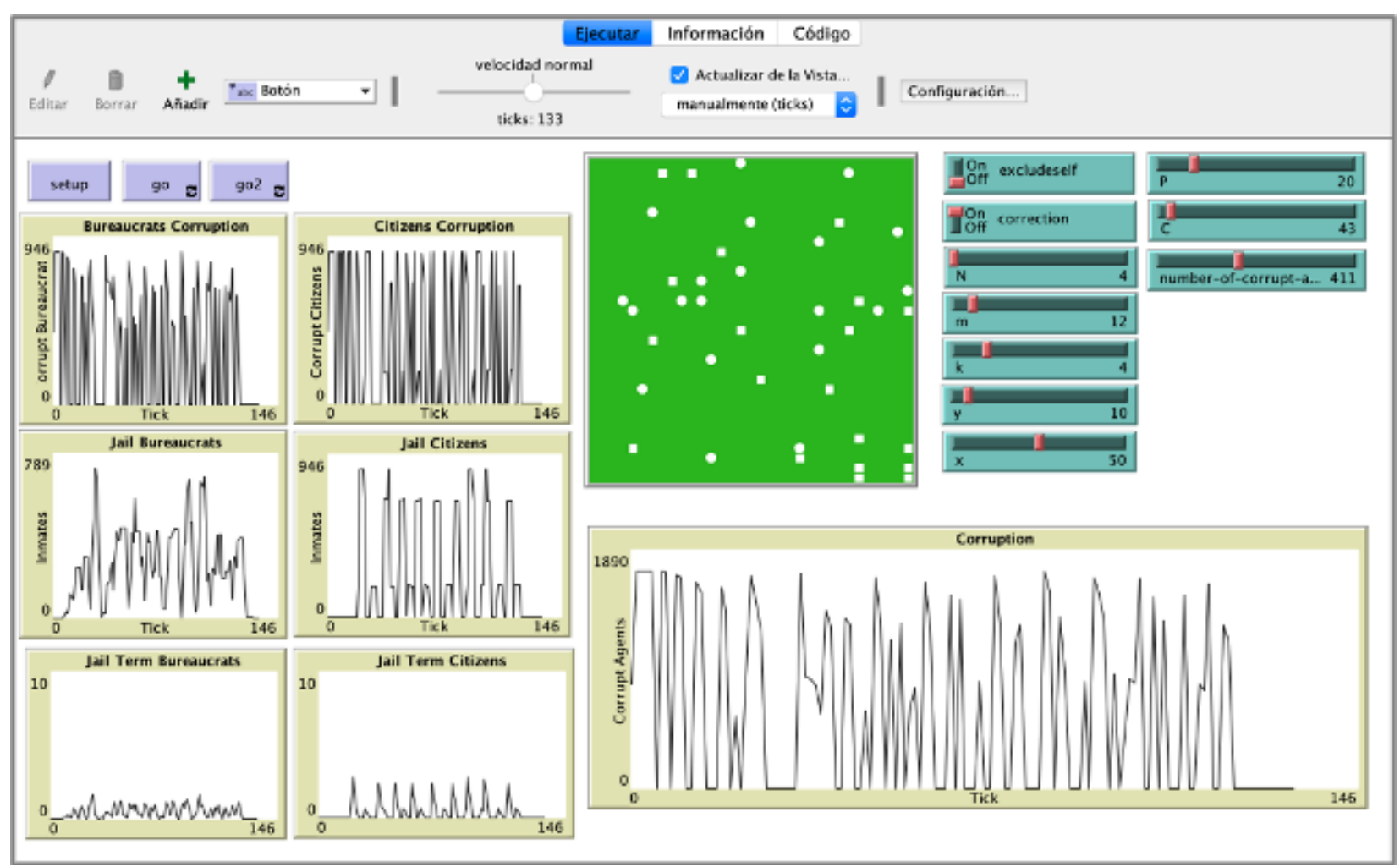

Figure 2. ABM to explain a trend

Source Adapted from (Godet, 1995a)

The following requirements were taken into account to micro-level:

Using Cl practices (Agami et al., 2009; Calof, 2015; Turner, 2005), the main objective is to collect recognized information, doing an environmental scan to identify weak signals and trends and key problems. A basic intelligence collection plan (Bachelard, 1949) was made, which includes three basic steps: a) creating an initial intelligence image, b) finding what is missing in the image, and, c) mapping and prioritize the sources. The collection plan is a cyclical process that must be constantly updated, since any new information generates new needs to know.

A set of heterogeneous sources was chosen to make a data collection such as: Suppliers evaluations, documents from multiple sources, news from newspapers and specialized websites, WhatsApp messages, operational tasks and payment flows, reports of activities in CSR, and customer service requests, among others. Social network monitoring and web scraping.

A set of chosen algorithms are: factor analysis, PCA, ICA, latent semantic analysis, social network analysis, text mining, logistic regression, tree models, ridge regression and lasso, SVM, inference algorithms in graphics and cluster analysis.

A set of packages was used in R, which included among others the following: ade4, boot, d3heatmap, dplyr, e1071, FactoClass, FactoMineR, ggBubbles, gghalves, glmnet, gplots, igraph, LSAfun, MASS, Matrix, openxlsx, psych, randomForest, RColorBrewer, rgl, RSpectra, rvest, shape, tibble, tidytext, tm, tree.

The set of algorithms was applied to achieve five objectives: 1) Using of principal component analysis and factor analysis for data feature extraction. 2) Applying topic modeling to discover patterns of word usage and how to connect contents/documents that share similar patterns to understand the spread of influence and the flow of the topics through a network. 3) Using the predictability of the logistic regression, to perform both variable selection and regularization to improve prediction accuracy and interpretability of the statistical model. 4) Using data visualization methods to graphically represent data from four or more variables on 2D/3D heatmaps, boxplot diagrams and bubbles. 5) Classifying similar data into groups.

These activities are carried out not only within the limits of the futuribles, to reflect the wide-ranging scanning and monitoring. Therefore, to reduce the weakness of the scenarios and the strategic formulation, their review should be carried out every time a set of key early alerts and weak signals that decision makers identify with a high strategic potential. Figure 3 shows a short version of the outcomes for the micro-level.

Creative thinking workshops were developed using tools (Barlow, 1989) for improvement and effective planning, combining brainstorm and affinity diagrams. These workshops used the results of DS for the micro-level and identified two new key factors for aggregation to the strategic design. There are: a) creation of social value among the communities where the projects are developed, and b) development of a traditional and emerging social business portfolio. For the meso level, the findings obtained from the micro level and the knowledge of the CSR team were used to build seven ABM. 


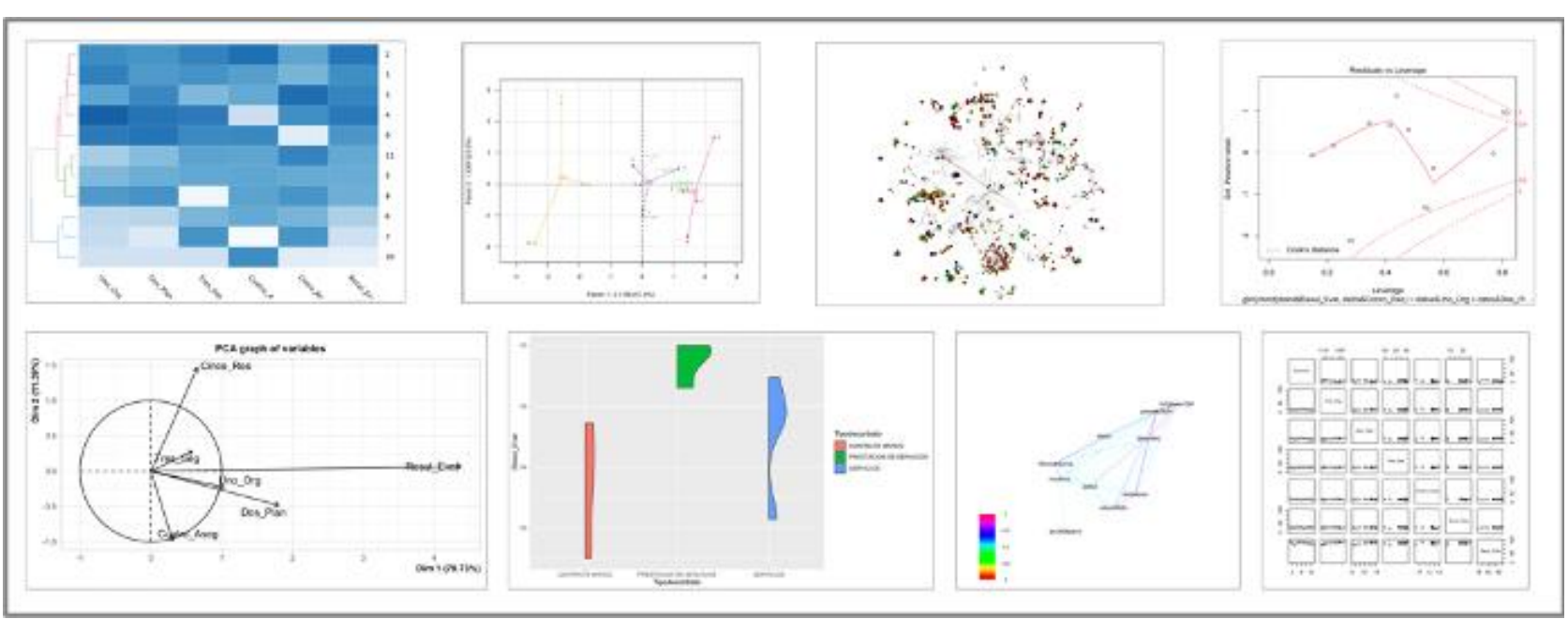

Figure 3. Outcomes for the micro-level

Table 1. FCM Matrix

\begin{tabular}{ccccccc}
\hline Key factor (KF) & $\mathbf{1}$ & $\mathbf{2}$ & $\mathbf{3}$ & $\mathbf{4}$ & 0.63 & 0.63 \\
\hline $\mathbf{1}$ & 0 & 0.88 & 0.38 & 0.38 & 0.38 \\
\hline $\mathbf{2}$ & 0.38 & 0.63 & 0.38 & 0.13 & 0.63 & 0.38 \\
\hline $\mathbf{4}$ & 0.63 & 0.38 & 0.38 & 0.63 \\
\hline
\end{tabular}

Source: Adapted from (Schwarz, 2009)

Table 2. TIA Matrix

\begin{tabular}{|c|c|c|c|c|c|}
\hline List of events & $\begin{array}{c}\text { Possibility of occurrence of } \\
\text { the events }\end{array}$ & $\begin{array}{c}\text { Years to maximum } \\
\text { impact }\end{array}$ & Maximum impact & Years to residual impact & Residual impact \\
\hline \multicolumn{6}{|c|}{$\begin{array}{r}\text { Positive events } \\
\end{array}$} \\
\hline KF1 & 0.71 & 2 & 0.5 & 8 & 0.3 \\
\hline KF2 & 0.51 & 3 & 0.4 & 7 & 0.25 \\
\hline KF3 & 0.71 & 4 & 0.35 & 8 & 0.2 \\
\hline KF4 & 0.71 & 4 & 0.3 & 8 & 0.15 \\
\hline KF5 & 0.91 & 3 & 0.25 & 7 & 0.15 \\
\hline \multicolumn{6}{|c|}{ Negative events } \\
\hline KF1 & 0.71 & 1 & 0.55 & 5 & 0.25 \\
\hline KF2 & 0.91 & 1 & 0.5 & 5 & 0.3 \\
\hline KF3 & 0.51 & 1 & 0.45 & 6 & 0.35 \\
\hline KF4 & 0.51 & 1 & 0.4 & 4 & 0.2 \\
\hline KF5 & 0.51 & 1 & 0.35 & 4 & 0.15 \\
\hline
\end{tabular}

Source: Adapted from (Schwarz, 2009)

\section{Where are we Going?}

The FlightTS method helps develop two processes: (i) building a causal model of scenarios and (ii) exploring the future to identify and choose the more plausible futurible. The FLighTS model expresses an interactive combination between a cognitive notion of scenario and a set of positive or negative events (i.e. trends and phenomena). The findings obtained in the micro-level were associated with each of the five key factors using an aggregation procedure (Koyré, 1940). With this information and the expertise of the CSR team, a cognitive map of the strategic design was built (now with five key factors). Table 1 shows the FCM matrix.

Using the information available ABM-based on trends and phenomena, its impact was divided between positive and negative. Applying group decision making (GDM) technique, two matrices were constructed. Thus, Table 2 shows the TIA matrices.

\section{Cone of Futuribles}

The FLighTS method was executed (Yang et al., 2019) exposing the notion of cone of futuribles. The cone shows a set of time series for each of the key factors. Thus, a translation mechanism was used with the art of conjecture, to express coevolution as a set of hypotheses of future states, from the qualitative approach. To do this, extrapolations were made using the morphological analysis method (Agami et al., 2008). Figure 4 shows the cone of futuribles built for the oil company with a time horizon is 10 years ahead. 


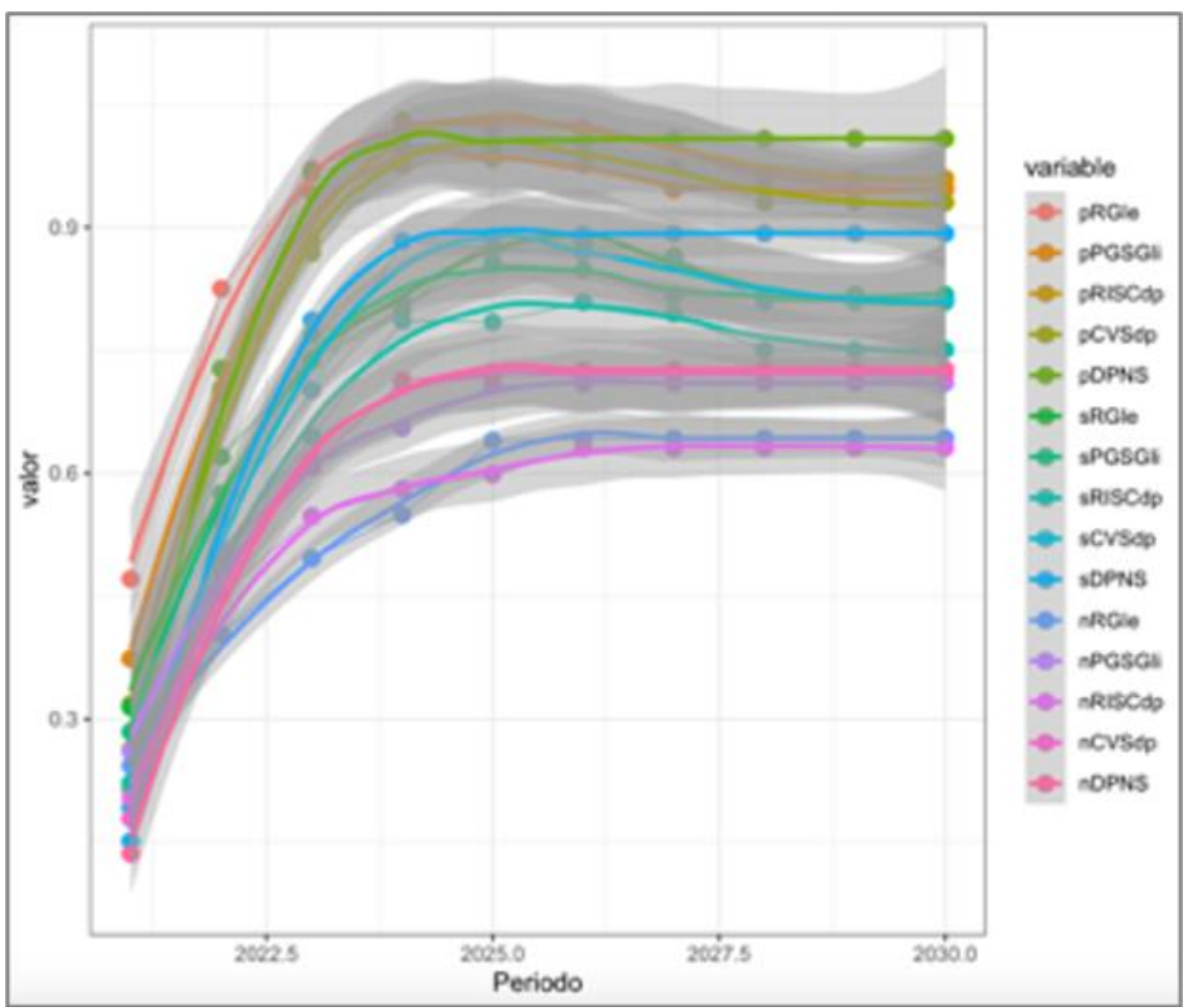

Figure 4. Cone of futuribles

The aggregation of the key factors offers a quantitative estimate of the state of the futuribles. Therefore, the coevolution of the key factor in the cone of futuribles illustrates a range between $145 \%$ and $242 \%$ relative improvement among the set of futuribles states ten years ahead. The result shows that the performance and results of the CSR team can be improved.

The identification of a present and future situation by each of the key factors of the strategic design used by the cone of futuribles, allows the CSR team to build a better strategic formulation, by improving the rules of relationship with local communities. The application of the ISSM framework becomes a cyclical process for the estimation of strategic purposes in CSR and the best performance of the operation for the oil company.

\section{CONCLUSIONS}

The development of an $\mathrm{Cl}$ architecture that integrates AI, DS and foresight, offers two relevant results for the implementation of an ISSM framework (Koyré, 1928): 1) Operational evaluation (Calof et al., 2018). It requires a cycle of refinement in the collection, processing and interpretation of data, based on the systematic collection of information from heterogeneous sources for the identification of endo- and exo-signal. The implications translate into operational and decision-making flexibility, as it promotes the development of renewed environmental monitoring practices, with an immediate impact on the operating conditions of the oil company. 2) Strategic adjustment (Kosko, 1986a). It requires the optimization of variables and parameters thanks to the use of DS, in addition to the use of ABM-based microsimulation to identify macro perspectives on the behavior of trends and phenomena. The implications translate into strategic and financial flexibility, by having an early understanding of the futuribles.

For the operational and strategic purposes of the oil company, five were the key findings: a) adopting of new forms of evaluation of the operation by adopting renewed environment monitoring practices, b) deepening in the understanding of organizational dynamics and communities in the territory, c) developing of knowledge assets based on microsimulation that explore the behavior of trends and phenomena, $d$ ) identifying of two new key factors that strengthen the strategic design for the CSR team and, e) developing of a new way of strategic monitoring.

\section{REFERENCES}

Ackoff, R. L. (1981). Creating the Corporate Future. John Wiley \& Sons, Philadelphia.

Agami, N., Atiya, A., Saleh, M. and El-Shishiny, H. (2009). A neural network based dynamic forecasting model for Trend Impact Analysis. Technological Forecasting and Social Change, 76(7), 952-962. https://doi.org/10.1016/j.techfore.2008.12.004 
Agami, N., Omran, A., Saleh, M. and El-Shishiny, H. (2008). An enhanced approach for trend impact analysis. Technological forecasting and social change, 75(9), 1439-1450. https://doi.org/10.1016/j.techfore.2008.03.006

Agami, N., Saleh, M. and El-Shishiny, H. (2010). A fuzzy logic based trend impact analysis method. Technological Forecasting and Social Change, 77(7), 1051-1060. https://doi.org/10.1016/j.techfore.2010.04.009

Amer, M., Daim, T. and Jetter, A. (2013). A review of scenario planning. Futures, 26, $23-40$. https://doi.org/10.1016/j.futures.2012.10.003

Ansoff, H. I. (1975). Managing Strategic Suprise by Response to Weak Signals. California. Management Review, XVIII(2), 21-33. https://doi.org/10.2307/41164635

Bachelard, G. (1936). Le Surrationalisme, dans Inquisitions [revue], repris dans tudes. Paris.

Bachelard, G. (1949). Le Rationalisme appliqu. Paris 3, france: Presses Universitaires.

Barlow, H. B. (1989). Unsupervised learning. Neural computation, 1(3), 295-311. https://doi.org/10.1162/neco.1989.1.3.295

Bekey, G. A. and Kogan, B. J. (Eds.). (2012). Modeling and simulation: Theory and practice: A memorial volume for professor Walter J. Karplus (1927-2001). Springer Science \& Business Media.

Berger, G. (1957). Sciences humaines et prévision. Revue des Deux Mondes, 1829-1971, 417-426.

Cabezas, R. T. and Verdegay, J. L. (2019, June). Intelligent System of Strategic Monitoring. In 2019 14th Iberian Conference on Information Systems and Technologies (CISTI) (pp. 1-6). IEEE. https://doi.org/10.23919/CISTI.2019.8760643

Calof, J. (2015). Creating impactful intelligence: Communication lessons from the corporate environment. In Intelligence Communication in the Digital Era: Transforming Security, Defence and Business (pp. 72-87). Palgrave Pivot, London. https://doi.org/10.1057/9781137523792_6

Calof, J., Arcos, R. and Sewdass, N. (2018). Competitive intelligence practices of European firms. Technology Analysis \& Strategic Management, 30(6), 658-671. https://doi.org/10.1080/09537325.2017.1337890

Calof, J., Richards, G. and Smith, J. (2015). Foresight, competitive intelligence and business analytics-tools for making industrial programmes more efficient. Foresight, 9(1 (eng)). https://doi.org/10.17323/1995-459X.2015.1.68.81

Carlsson, C. and Fullér, R. (1996, October). Adaptive fuzzy cognitive maps for hyperknowledge representation in strategy formation process. In Procs. of the Int'l Panel Conf. on Soft and Intelligent Comp. (43-50).

De Jouvenel, B. (1967). Arte della congettura. Florencia: Vallecchi Editore.

Díaz-Fernández, M. C., González-Rodríguez, M. R. and Simonetti, B. (2019). The moderating role of top management team diversity in strategic change in a multicultural context. European Management Review, 16(4), 957-973. https://doi.org/10.1111/emre.12306

Dickerson, J. and Kosko, B. (1994). Virtual worlds as fuzzy cognitive maps. Presence: Teleoperators \& Virtual Environments, 3(2), 173-189. https://doi.org/10.1162/pres.1994.3.2.173

Dzutsati, V. (2019). An Agent-Based Model of Corruption: Micro Approach (version 1.1.0). Retrieved October 5, 2019 from the Computational Model Library: https://www.comses.net/codebases/4520/releases/1.1.0/

Fernández, Y., Cruz, C. and Verdegay, J. L. (2018). A new model based on soft computing for evaluation and selection of software products. IEEE Latin America Transactions, 16(4), 1186-1192. https://doi.org/10.1109/TLA.2018.8362155

Forrester, J. W. (1970). Urban dynamics. IMR; Industrial Management Review (Pre-1986), 11(3), 67.

Ghifary, M., Kleijn, W. B., Zhang, M., Balduzzi, D. and Li, W. (2016, October). Deep reconstruction-classification networks for unsupervised domain adaptation. In European Conference on Computer Vision (pp. 597-613). Springer, Cham. https://doi.org/10.1007/978-3-319-46493-0_36

Gilad, B. (2006). Strategic Early Warning. Competitive Intelligence Magazine, 9(2), 14-17

Goal QPC (2019). Retrieved November 15, 2019 from the GOAL QPC. Memory Jogger. https://goalqpc.com

Godet, M. (1995a). Estrategia y gestión competitiva, de la anticipación de la acción: manual de prospectiva y estrategia. (Alfaomega, Ed.).

Godet, M. and Roubelat, F. (1996). Creating the future: the use and misuse of scenarios. Long Range Plan, 29(2), 164-171. https://doi.org/10.1016/0024-6301(96)00004-0

Gordon, T. and Hayward, H. (1968). Initial experiments with the cross impact matrix method of forecasting. Futures, 1(2), $100-116$. https://doi.org/10.1016/S0016-3287(68)80003-5

Gordon, T., Becker, H. and Gerjuoy, H. (1974). Trend impact analysis: anew forecasting tool. Futures Group.

Husserl, E. (1931). Méditations cartésiennes: introduction à la phénoménologie.

Husserl, E. (1936). HuDie Krisis der europe aischen Wissenschaften und die tranzendentale Pheanomenologie. Eine Einleitung in die phe anomenologische Philosophie. W. Biemel (hrsg), 2, 77-176.

Kosko, B. (1986a). Fuzzy cognitive maps. International Journal of Man-Machine Studies, 24(1), 65-75. https://doi.org/10.1016/S00207373(86)80040-2

Kosko, B. (1986b). Fuzzy knowledge combination. International Journal of Intelligent Systems, 1(4), $293-320$. https://doi.org/10.1002/int.4550010405

Koyré, A. (1928). La philosophie de Jacob Boehme. Paris 3. 


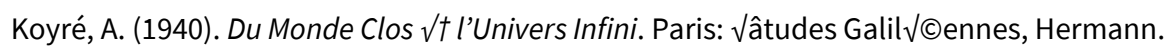

Leder, H (2010). Primary source intelligence in a collection plan. Retrieved from the SCIP - Strategic \& Competitive Intelligence Professionals: https://www.scip.org

Marcel, G. (1926). Journal métaphysique, 10.

Marcel, G. and Segond, J. (1935). Être et avoir. Les Études philosophiques, 9(1/2), 48-53.

Meadows, D. H. (1989). System dynamics meets the press. System Dynamics Review, 5(1), 69-80. https://doi.org/10.1002/sdr.4260050106

Ratzé, C., Gillet, F., Müller, J. P. and Stoffel, K. (2007). Simulation modelling of ecological hierarchies in constructive dynamical systems. Ecological complexity, 4(1-2), 13-25. https://doi.org/10.1016/j.ecocom.2007.02.014

Raynor, M. E. (2004). Strategic Flexibility: Taking the Fork in the Road. Competitive Intelligence Magazine, 7(1), 6-13.

Reinhardt, W. A. (1984). An early warning system for strategic planning. Long Range Planning, 17(5), $25-34$. https://doi.org/10.1016/0024-6301(84)90034-7

Schwarz, J. O. (2005). Pitfalls in implementing a strategic early warning system. Foresight.

Schwarz, J. O. (2009). „Schwache Signale “in Unternehmen: Irrtümer, Irritationen und Innovationen. In Zukunftsforschung und Zukunftsgestaltung (pp. 245-254). Springer, Berlin, Heidelberg. https://doi.org/10.1007/978-3-540-78564-4_18

Škulj, J. (2012). Complexity, Literature, Sciences: Initial Remarks on Discourse and Dialogue. Primerjalna književnost, 35(2).

Slaughter, R. (1988). Recovering the future. Melbourne, VIC: Graduate School of Environmental Science, Monash University.

Trujillo-Cabezas, R. (2008). El campo de los estudios de futuro: Contrastación entre el foresight y la prospectiva. Bogotá: Convenio Andrés Bello - Universidad Externado de Colombia.

Trujillo-Cabezas, R. (2020). Towards the development of future trend scenarios through dynamic analysis: A proposal of integration of Artificial Intelligence, Data Sciences and the field of Futures Studies to adapt to new environments. 2020 15th Iberian Conference on Information Systems and Technologies (CISTI), Sevilla, Spain, pp. 1-6. https://doi.org/10.23919/CISTI49556.2020.9140880

Trujillo-Cabezas, R. and Verdegay, J. L. (2019). Integrating Soft Computing into Strategic Foresight Methods: Towards an Adaptive Learning Environment Supported by Futures Studies (Vol. 387). Springer Nature. https://doi.org/10.1007/978-3-030-25432-2

Trujillo-Cabezas, R. and Verdegay, J. L. (2020). Modeling and Simulation of the Future. In Integrating Soft Computing into Strategic Foresight Methods (pp. 113-147). Springer, Cham. https://doi.org/10.1007/978-3-030-25432-2_5

Trujillo-Cabezas, R. and Verdegay, J. L. (2020). Strategic Foresight: Definitions and Key Concepts. In Integrating Soft Computing into Strategic Foresight Methods (pp. 29-41). Springer, Cham. https://doi.org/10.1007/978-3-030-25432-2_2

Turner, M. A. (2005). Why secret intelligence fails. Potomac Books, Inc.

Yang, L., Xu, C. and Wan, G. (2019). Exploring the impact of TMTs' overseas experiences on innovation performance of Chinese enterprises. Chinese Management Studies, 13(4), 1044-1085. https://doi.org/10.1108/CMS-12-2018-0791 